\title{
Bulk-Fill Composite Restorations Step-by-Step Description of Clinical Restorative Techniques Case Reports
}

\section{Restauraciones compuestas Bulk-Fill Descripción paso a paso de las técnicas de restauración clínica Informes de casos}

Renata Vasconcelos Monteiro DDS, MS, PhD Student ${ }^{1}$;

Carolina Mayumi Cavalcanti Taguchi DDS, MS, PhD Student ${ }^{1}$; Renata Gondo Machado DDS, MS, PhD²; Silvana Batalha Silva DDS, MS, PhD²; Jussara Karina Bernardon DDS, MS, PhD²; Sylvio Monteiro Junior DDS, MS, PhD²

1. PhD Student, Department of Operative Dentistry, School of Dentistry, Federal University of Santa Catarina, Florianopolis, Brazil.

2. Professor, Department of Operative Dentistry, School of Dentistry, Federal University of Santa Catarina, Florianopolis, Brazil.

Correspondence to: Dra. Renata Vasconcelos Monteiro - renatavasmonte29@gmail.com

Received: 21-II-2019

Accepted: $15-$ III-2019

Published Online First: 22-III-2019

DOI: 10.15517/IJDS.V0I0.36681

\section{ABSTRACT}

Composite resins are excellent materials for direct restorations in the posterior region, satisfactorily reestablishing esthetics and function. Recently, a new class of composites has been commercialized, the so-called Bulk-fill resins. These resins may be inserted in the dental cavity in increments of 4 to $5 \mathrm{~mm}$ thick, and have the advantages of reducing polymerization shrinkage and clinical working time. The aim of this case report was to describe the use of bulk-fill composite resins to restore Class I and Class II cavities by means of two different restorative techniques.

\section{KEYWORDS}

Dental restoration; Resin composite; Bulk-fill resin. 


\section{RESUMEN}

Las resinas compuestas son excelentes materiales para restauraciones directas en la región posterior, restableciendo satisfactoriamente la estética y la función. Recientemente, se ha comercializado una nueva clase de compuestos, las denominadas resinas Bulk Fill. Estas resinas pueden insertarse en la cavidad dental en incrementos de 4 a $5 \mathrm{~mm}$ de espesor, y tienen las ventajas de reducir la contracción de la polimerización y el tiempo de trabajo clínico. El objetivo de este informe de caso fue describir el uso de resinas Bulk fill para restaurar las cavidades de Clase I y Clase II mediante dos técnicas de restauración diferentes.

\section{PALABRAS CLAVE}

Restauración dental; Compuesto de resina; Resina Bulk Fill.

\section{INTRODUCTION}

Composite resins have undergone significant evolution since they were first introduced into dentistry (1). Changes in the monomer matrix and filler particles of composites have been made in an attempt to reduce polymerization shrinkage and improve their wear resistance (2-4).

Polymerization shrinkage is the major disadvantage of using composites $(2,5,6)$, since it creates stresses between tooth and restoration, leading to failures at the adhesive interface, microgaps and cuspid deflection (7-9). The stresses resulted from this shrinkage may be manifested clinically as hypersensitivity, pulpitis, secondary caries and enamel microfissures, then reducing the longevity of restorations (10-12).

In the effort to reduce shrinkage stress, it has been indicated that composite resins should be inserted in the cavity in increments of $2 \mathrm{~mm}$ maximum thickness (the incremental technique). By means of this technique, a lower number of walls are united, diminishing the cavity configuration factor, known as C factor $(7,11,13)$. However, the incremental insertion method has some disadvantages, such as the possibility of the incorporation of air bubbles, bond failures and contamination among the composite increments, in addition of requiring a longer clinical time to perform the restoration $(7,14)$.

To overcome the disadvantages of the conventional composites, bulk-fill composite resins have been introduced. Those may be inserted in the dental cavity in increments of $4 \mathrm{~mm}$ up to $5 \mathrm{~mm}$ thick $(10,11)$. Rosatto et al. (15), in their study, assessed Bulk-fill resin restorations in posterior teeth and found reduced deflection of the cuspid, polymerization shrinkage and shrinkage stresses, increasing the fracture strength. Thus, the authors suggested that Bulk-fill resins might be safely indicated for restorations in posterior teeth. Furthermore, various studies have reported satisfactory performance of Bulk-fill restorations in posterior teeth, presenting results similar to those of conventional composite resins (16-18).

Therefore, the aim of this case report was to describe the step-by-step procedure to perform Class I and Class II with Bulk-fill composite resin throught two different restorative techniques.

\section{CASE REPORT}

A 25-year-old man attended to the dental clinic for routine exams, reporting tooth sensitivity while ingesting cold and sweet aliments. On intraoral exam, possible non-cavitated caries 
lesions were observed. The lesions were confirmed through interproximal radiographic exam, which revealed large lesions in dentin on maxillary right second premolar (Figures 1a and 1b) and mandibular left first molar (Figures 2a and 2b). Once the caries lesions were deep in dentin, the authors opted for removal of the carious tissue and direct restoration with bulk-fill composite.

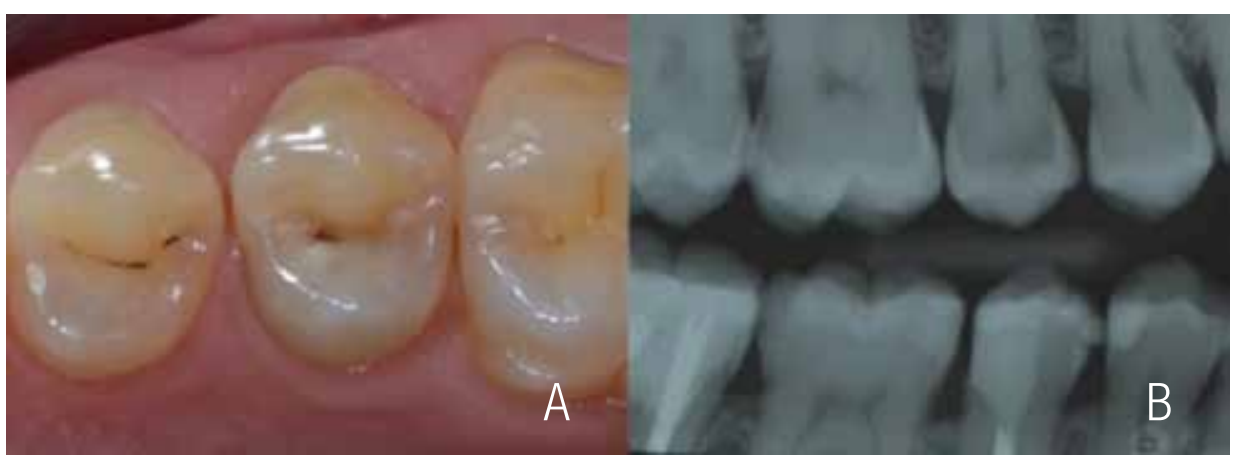

Figure 1. a: Clinical aspect: presence of caries lesion on occlusal surface of the maxillary right second premolar. b: Interproximal radiograph of right premolar, showing lesion in dentin of the maxillary right second premolar.

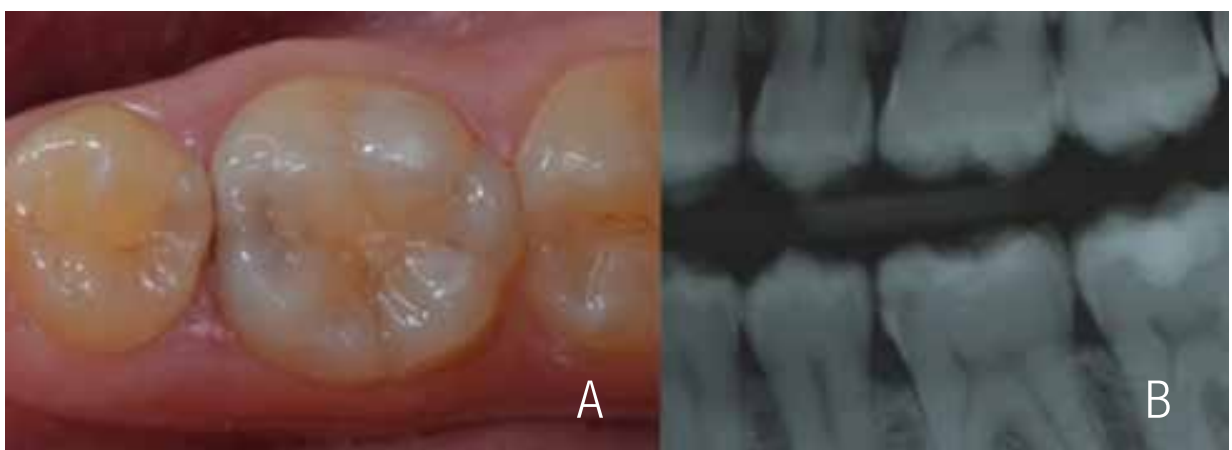

Figure 2. a: Initial aspect: presence of occlusal-mesial (OM) lesion of the mandibular left first molar. b: Interproximal radiograph of left molar, showing lesion in dentin of the mandibular left first molar.

RESTORATIVE PROTOCOL FOR THE MAXILLARY RIGHT SECOND PREMOLAR - BULK-FILL TECHNIQUE

After anesthesia (Mepinor 2\%, Nova DFL, Rio de Janeiro, RJ, Brazil) and rubber dam isolation (Hevea, Angelus, Londrina, PR, Brazil) of the operative area, access to the caries lesion was obtained with a high speed spherical diamond bur. The caries lesion removal was performed with dentin curettes and low speed spherical bur (Figure 3a).
After removing the lesion, the enamel was selectively etched with 37\% phosphoric acid (Power Etching, BM4, Palhoça, SC, Brazil), for 30 seconds (Figure 3b). Then Single Bond Universal adhesive (3M ESPE, St. Paul, MN, USA) system was applied on enamel and dentin for 20 seconds with an applicator brush (Figure 3c). The adhesive was light activated for 10 seconds with a LED polymerizing unit (Radii-Cal - SDI, Bayswater, Victoria, Australia) with a power of $1200 \mathrm{~mW} / \mathrm{cm} 2$, in accordance with the manufacturer's indications. A single portion of Filtek Bulk Fill (3M ESPE, St. 
Paul, MN, USA) composite resin, shade A3 was placed and compressed in the dental cavity (Figure $3 d)$. The occlusal surface was sculpted and then light polymerized for 40 seconds.

After final light polymerization, the rubber dam was removed and occlusal adjustment was proceeded using $3118 \mathrm{FF}$ diamond bur (KG Sorensen, Barueri, SP, Brazil). In the subsequent consultation appointment, finishing and polishing was performed with diamond burs and abrasive rubbers (Enhance, Dentsply, Milford, USA). The final appearance observed after one week of control was extremely satisfactory, as seen in Figure 4.

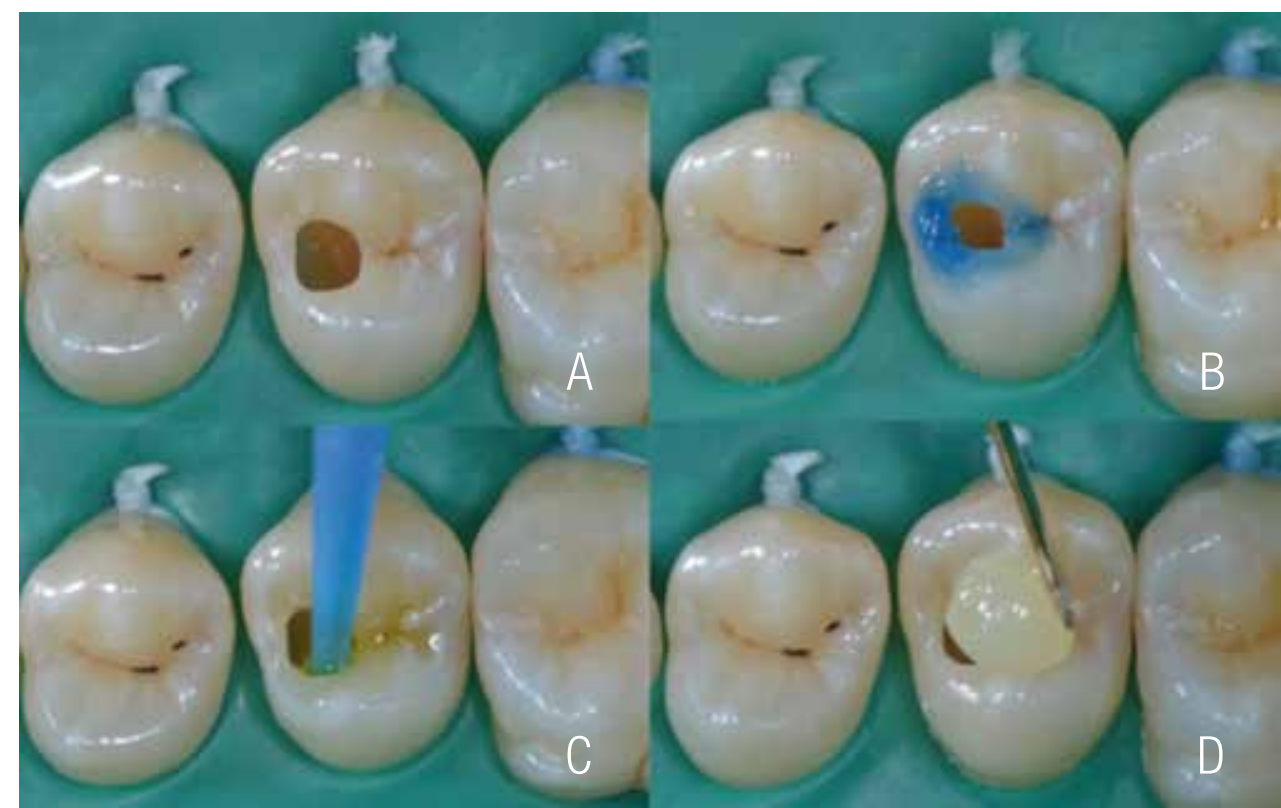

Figure 3. a: Aspect after carious tissue removal. b. Selective conditioning of enamel. c. Application of universal adhesive system. $d$. Resin inserted in a single increment.

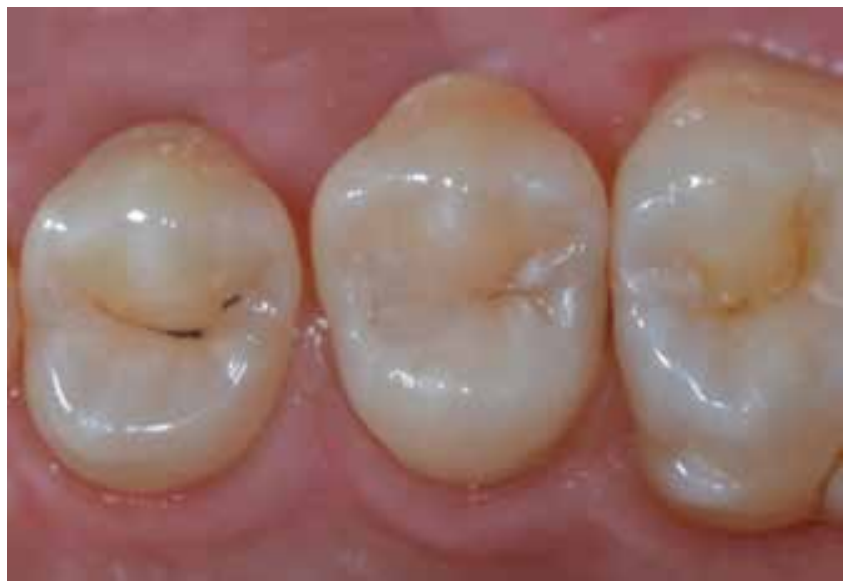

Figure 4. Final aspect of the restoration. 
RESTORATIVE PROTOCOL FOR THE MANDIBULAR LEFT FIRST MOLAR - "SANDWICH TECHNIQUE"

After anesthesia and rubber dam isolation of the operative area, access to the caries lesion was obtained through the occlusal sulcus with a high speed spherical diamond bur. The caries lesion was removed with dentin curettes and low speed round bur. Due to the enamel fragility of the enamel, the marginal crest was removed, resulting in a Class II cavity (Figure 5a).

After selective enamel etching with 37\% phosphoric acid (Power Etching, BM4, Palhoça, SC, Brazil), Tetric N-bond Universal adhesive (IvoclarVivadent, Schaan, Liechtenstein) system was applied for 20 seconds with an applicator brush and light activated for 10 seconds with LED light polymerizing unit $(1200 \mathrm{~mW} / \mathrm{cm} 2)$, which was in accordance with the manufacturer's indications. A biconvex partial metal matrix was inserted and stabilized with elastic shim, and a metal ring was placed to improve the matrix adaptation to the tooth.
To restore this cavity, the "Sandwich" technique was used. One single portion of Tetric N-Ceram Bulk fill (Ivoclar-Vivadent, Schaan, Liechtenstein) resin composite shade A3 was inserted into the cavity, maintaining a free space of approximately $2 \mathrm{~mm}$ for the enamel resin layer, and light polymerized for 10 seconds. Then, an increment of Empress Direct (Ivoclar-Vivadent, Barueri, SP, Brazil) conventional resin composite shade A3 was inserted into the remaining dental cavity (Figure 5b). The anatomic characteristics of the occlusal surface were reestablished with a metallic spatula and a brush, followed by light polymerization for 20 seconds.

After final light polymerization, the rubber dam was removed and the occlusal adjustment was proceeded with a 3118 FF diamond bur. In the subsequent consultation, finishing and polishing was performed with diamond burs and abrasive rubbers. The final aspect observed after one week of control was extremely satisfactory as seen in Figure 6.

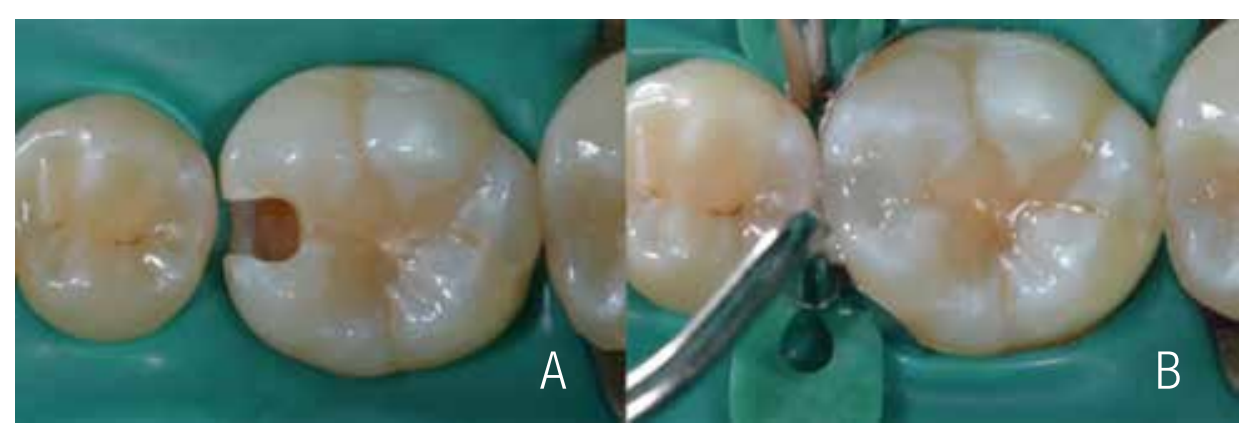

Figure 5. a. Class II preparation after removal of carious tissue. b. Application of a coating layer of resin. 


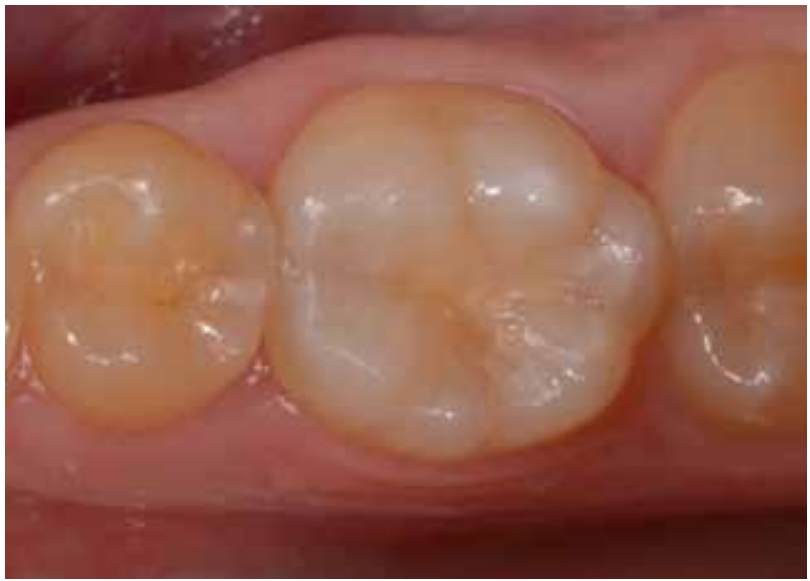

Figure 6. Final aspect of restoration after finishing and polishing.

\section{DISCUSSION}

Bulk-Fill composite resins have modulators of polymerization chemical groups and plasticizing monomers in their composition, which are capable of reducing the stress caused by polymerization shrinkage (15,19-21). In addition, the presence of potent photoinitiators and the transparency of these composites allow efficient depth polymerization (22-24). Thus, these composites may be inserted in dental cavities in a single bulk up to 4 to $5 \mathrm{~mm}$ thick instead of the incremental technique of 2 $\mathrm{mm}$, thereby reducing the clinical working time (25-27).

The bulk-fill composite polymerization is similar to that of resins inserted by the incremental technique $(20,21)$. According to Li $X$ et al. (22) Bulk-Fill resins can be efficiently polymerized up to $4 \mathrm{~mm}$ depth, while in conventional composites, adequate polymerization is achieved when the increments are $2 \mathrm{~mm}$ maximum thickness. The cavity depth in the two above-mentioned cases was of approximately $4 \mathrm{~mm}$, which enabled the insertion in a single increment.

Bulk-fill composites are more translucent than the conventional resins (22-24). Consequently, this high level of translucence might have a negative influence on esthetic appearance since the insertion in a single increment preclude the stratification. Nevertheless, in the cases described above, this limitation was not relevant once the restorations were performed in posterior teeth and the result was esthetically satisfactory.

The translucence of Bulk-fill composites is related to the quantity of inorganic matrix filler (28). Reduced quantity of filler results in increased degree of translucence and irradiance of light transmitted, and consequently increased polymerization efficiency (22). However, reduction in the quantity of filler negatively affects the mechanical properties of the composites (19). Although the enhanced light transmission improves the possibility of inserting thicker increments, a high level of mechanical properties increases the clinical longevity of restorations (24). Therefore, these are factors to be considered, particularly in restorations performed in posterior teeth.

The mechanical stability of restorations performed with bulk-fill composites is still an open question, since there are no long-term clinical studies available yet (29). Ilie \& Fleming (30) observed an increase in the micromechanical properties of bulk-fill composites when compared with conventional resins, probably due to the improved filler content of bulk-fill materials. However, Leprince et al. (19) observed the mechanical 
properties of bulk-fill composites were much lower when compared with those of conventional composite resins, and highlighted the importance of adding a last covering layer with conventional resin to reduce the surface wear of the restoration, as was performed in the second case reported here.

In order to simplify and reduce the working time, universal adhesives were used in both cases presented this clinical report. In essence, universal adhesives are self-etching and can either be associated with previous phosphoric acid etching, or not (31-33).

The bond to enamel is generally more efficient than dentin with phosphoric acid etching (32, 34-36). Frankenberger et al. (33) observed the performance of bond self-etching adhesives was improved when phosphoric acid was selectively applied to the enamel. However, etching the dentin before the application of a universal adhesive did not improve the bond efficiency $(37,38)$. According to Jang et al. (39), universal adhesives may guarantee a reliable bond to dentin, regardless the application method.

Self-etching adhesives have the capacity to condition the dental structures due to the presence of acid monomers in their composition $(31,40,41)$. Nevertheless, these adhesives have a reduced conditioning potential when compared with etchand-rinse systems, leaving a large portion of the dentinal tubules obstructed with smear layer residues and contributing to less post-operative sensitivity $(37,40,41)$. Thus, selective conditioning of enamel is recommended prior the application of a universal adhesive, as a recommendable strategy for optimizing the bond strength (37).

\section{CONCLUSION}

In the present clinical cases, Class I and Class II dental cavity restorations with Bulk fill composites proved to be a simple and fast technique with good esthetic and functional results.

\section{REFERENCES}

1. Bayne S. C. Beginnings of the dental composite revolution. J Am Dent Assoc. 2013; 144 (8): 880-884.

2. Gonçalves F., Pfeifer C. S., Ferracane J. L., Braga RR. Contraction Stress Determinants in Dimethacrylate Composites. J Dent Res. 2008; 87 (4): 367-371.

3. Ilie N., Hickel R. Resin composite restorative materials. Aust. dent. j. 2011; 56: (1 Suppl): 59-66.

4. Ferracane J. L. Resin composite-State of the art. Dent Mater. 2011; 27 (1): 29-38.

5. Al Sunbul H., Silikas N., Watts D. C. Polymerization shrinkage kinetics and shrinkage-stress in dental resin-composites. Dent Mater. 2016; 32 (8): 998-1006.

6. Lee I. B., Cho B. H., Son H. H., Um C. M. A new method to measure the polymerization shrinkage kinetics of light cured composites. J. oral rehabil. 2005; 32 (4): 304-314.

7. Park J., Chang J., Ferracane J., Bog I. How should composite be layered to reduce shrinkage stress: Incremental or bulk filling? Dent Mater. 2008; 24 (11): 1501-1505.

8. Kaisarly D., Gezawi M. El. Polymerization shrinkage assessment of dental resin composites: a literature review. Odontology. 2016; 104 (3): 257-270.

9. Kwon Y., Ferracane J., Lee I. Effect of layering methods, composite type, and flowable liner on the polymerization shrinkage stress of light cured composites. Dent Mater. 2012; 28 (7): 801-809.

10. Braga R. R., Ferracane J. L. Alternatives in polymerization contraction stress management. Crit Rev Oral Biol Med. 2004; 15 (3): 176-184.

11. Ferracane J. L. Buonocore Lecture. Placing dental composites--a stressful experience. Oper Dent. 2008; 33 (3): 247-257. 
12. Dauvillier B. S., Aarnts M. P., Feilzer A. J. Developments in shrinkage control of adhesive restoratives. J Esthet Dent. 2000; 12 (6): 291-299.

13. Lee M. R.1, Cho B. H., Son H. H., Um C. M., Lee I. B. Influence of cavity dimension and restoration methods on the cusp deflection of premolars in composite restoration. Dent Mater. 2007; 23 (3): 288-295.

14. Abbas G., Fleming G. J., Harrington E., Shortall A. C., Burke F. J. Cuspal movement and microleakage in premolar teeth restored with a packable composite cured in bulk or in increments. J Dent. 2003; 31 (6): 437-444.

15. Rosatto C. M., Bicalho A. A., Veríssimo C., Bragança G. F., Rodrigues M. P., Tantbirojn D., Versluis A., Soares C. J. Mechanical properties, shrinkage stress, cuspal strain and fracture resistance of molars restored with bulk-fill composites and incremental filling technique. J Dent. 2015; 43 (12): 1519-1528.

16. Van Dijken J. W., Pallesen U. Posterior bulkfilled resin composite restorations: A 5 year randomized controlled clinical study. J Dent. 2016; 51: 29-35.

17. Heintze S. D., Monreal D., Peschke A. Marginal Quality of Class II Composite Restorations Placed in Bulk Compared to an Incremental Technique: Evaluation with SEM and Stereomicroscope. J Adhes Dent. 2015; 17 (2): 147-154.

18. Rauber G. B., Bernardon J. K., Vieira L. C., Maia H. P., Horn F., Roesler C. R. In Vitro Fatigue Resistance of Teeth Restored With Bulk Fill versus Conventional Composite Resin. Braz Dent J. 2016; 27 (4): 452-457.

19. Leprince J. G., Palin W. M., Vanacker J., Sabbagh J., Devaux J., Leloup G. Physicomechanical characteristics of commercially available bulk-fill composites. J Dent. 2014; 42 (8): 993-1000.
20. Goracci C., Cadenaro M., Fontanive L., Giangrosso G., Juloski J., Vichi A., Ferrari F. Polymerization efficiency and flexural strength of low-stress restorative composites. Dent Mater. 2014; 30 (6): 688-694.

21. El-Damanhoury H., Platt J. Polymerization shrinkage stress kinetics and related properties of bulk-fill resin composites. Oper Dent. 2014; 39 (4): 374-382.

22. Li X., Pongprueksa P., Van Meerbeek B., De Munck J. Curing profile of bulk-fill resin-based composites. J Dent. 2015; 43 (6): 664-672.

23. Son S. A., Park J. K., Seo D. G., Ko C. C., Kwon Y. H. How light attenuation and filler content affect the microhardness and polymerization shrinkage and translucency of bulk-fill composites? Clin Oral Investig. 2017; 21 (2): 559-565.

24. Bucuta S., Ilie N. Light transmittance and micro-mechanical properties of bulk fill vs. conventional resin based composites. Clin Oral Investig. 2014; 18 (8): 1991-2000.

25. Alrahlah A., Silikas N., Watts D. C. Post-cure depth of cure of bulk fill dentalresin-composites. Dent Mater. 2014; 30 (2): 149-154.

26. Flury S., Hayoz S., Peutzfeldt A., Hüsler J., Lussi A. Depth of cure of resin composites: Is the ISO 4049 method suitable for bulk fill materials? Dent Mater. 2012; 28 (5): 521-528.

27. Yu P., Yap A., Wang X. Y. Degree of Conversion and Polymerization Shrinkage of Bulk-Fill Resin-Based Composites. Oper Dent. 2017; 42 (1): 82-89.

28. Lee Y. K. Influence of filler on the difference between the transmitted and reflected colors of experimental resin composites. Dent Mater. 2008; 24 (9): 1243-1247.

29. Ilie N., Bucuta S., Draenert M. Bulk-fill resinbased composites: an in vitro assessment of their mechanical performance. Oper Dent. 2013; 38 (6): 618-625. 
30. Ilie N., Fleming G. J. In vitro comparison of polymerisation kinetics and the micromechanical properties of low and high viscosity giomers and RBC materials. J Dent. 2015; 43 (7): 814-822.

31. Sezinando A., Luque-Martinez I., Muñoz M. A., Reis A., Loguercio A. D., Perdigão J. Influence of a hydrophobic resin coating on the immediate and 6-month dentin bonding of three universal adhesives. Dent Mater. 2015; 31 (10): e236-246.

32. Hanabusa M., Mine A., Kuboki T., Momoi Y., Van Ende A., Van Meerbeek B., De Munck J. Bonding effectiveness of a new 'multi-mode' adhesive to enamel and dentine. J Dent. 2012; 40 (6): 475-484.

33. Frankenberger R., Lohbauer U., Roggendorf M. J., Naumann M., Taschner M. Selective enamel etching reconsidered: better than etch-and-rinse and self-etch? J Adhes Dent. 2008; 10 (5): 339-344.

34. Peumans M., De Munck J., Van Landuyt K. L., Poitevin A., Lambrechts P., Van Meerbeek B. Eight-year clinical evaluation of a 2-step self-etch adhesive with and without selective enamel etching. Dent Mater. 2010; 26 (12): 1176-1184.

35. Van Meerbeek B., Kanumilli P., De Munck J., Van Landuyt K., Lambrechts P., Peumans M. A randomized controlled study evaluating the effectiveness of a two-step self-etch adhesive with and without selective phosphoric-acid etching of enamel. Dent Mater. 2005; 21 (4): 375-383.

36. Rotta M., Bresciani P., Moura S. K., Grande R. H., Hilgert L. A., Baratieri L. N., Loguercio A. D., Reis A. Effects of phosphoric acid pretreatment and substitution of bonding resin on bonding effectiveness of self-etching systems to enamel. J Adhes Dent. 2007; 9 (6): 537-545.

37. Rosa W. L., Piva E., Silva A. F. Bond strength of universal adhesives: A systematic review and meta-analysis. J Dent. 2015; 43 (7) :765-776.

38. Marchesi G., Frassetto A., Mazzoni A., Apolonio F., Diolosà M., Cadenaro M., Di Lenarda R., Pashley D. H., Tay F., Breschi L. Adhesive performance of a multi-mode adhesive system: 1-year in vitro study. J Dent. 2014; 42 (5): 603-612.

39. Jang J. H., Lee M. G., Woo S. U., Lee C. O., Yi J. K., Kim D. S. Comparative study of the dentin bond strength of a new universal adhesive. Dent Mater J. 2016; 35 (4): 606-612.

40. Carvalho R. M., Chersoni S., Frankenberger R., Pashley D. H., Prati C., Tay F. R.Achallenge to the conventional wisdom that simultaneous etching and resin infiltration always occurs in self-etch adhesives. Biomaterials. 2005; 26 (9): 1035-1042.

41. Van Meerbeek B., Yoshihara K., Yoshida Y., Mine A., De Munck J., Van Landuyt K. L. State of the art of self-etch adhesives. Dent Mater. 2011; 27 (1): 17-28. 